\title{
A new species of Graphomya Robineau-Desvoidy (Diptera, Muscidae)
}

\author{
Márcia S. Couri ${ }^{1,2} \&$ Bianca Marques ${ }^{1}$ \\ ${ }^{1}$ Departamento de Entomologia, Museu Nacional. Quinta da Boa Vista, 20940-040 Rio de Janeiro, Rio de Janeiro, Brasil. \\ E-mail: mcouri@attglobal.net \\ 2 Research fellow of Conselho Nacional de Desenvolvimento Científico e Tecnológico, CNPq.
}

\begin{abstract}
Graphomya Robineau-Desvoidy is known from 12 neotropical species, only two of them with occurrence in Brazil. A new species from the Amazon is described and illustrated - G. amazonensis sp. nov. This is also the first record of the genus to the Amazon State, Brazil.

KEY WORDS. Amazon, G. amazonensis sp. nov., morphology, taxonomy.
\end{abstract}

RESUMO. Uma nova espécie de Graphomya Robineau-Desvoidy (Diptera, Muscidae). Graphomya RobineauDesvoidy é conhecido por 12 espécies neotropicais, apenas duas com ocorrência no Brasil. Uma nova espécie da Amazônia é descrita e ilustrada - G. amazonensis sp. nov. Este é também o primeiro registro do gênero para o Estado do Amazonas, Brasil.

PALAVRAS CHAVE. Amazonas, G. amazonensis sp. nov., morfologia, taxonomia.

Graphomya Robineau-Desvoidy is a neotropical genus known from 12 species, only two of them recorded to Brazil $-G$. analis (Macquart, 1851) and G. meridionalis Townsend, 1892. (CARvalHo et al. 2005)

COURI \& CARVALHO (2002) published a parcial key to the identification of three males and three females Graphomya species.

The aim of this paper is to add a new species from Brazil to Graphomya: G. amazonensis, sp. nov. and record the genus for the first time to the Amazon State, Brazil.

\section{MATERIAL AND METHODS}

The material examined belongs to Museu Nacional, Rio de Janeiro (Brazil) collection (MNRJ).

The terminalia were prepared in solution of potassium hydroxide at $10 \%$, in water-bath, for ten minutes. They were then dissected in glycerol and drawn and packed in microtube with glycerol and fixed to the pin together with the specimen.

\section{Graphomya amazonensis sp. nov.}

Colour. Dark brown with grey pollinosity. Head with frons, face, fronto-orbital plate and gena silver; antenna dark brown, arista brown; palpus dark brown. Mesonotum brown, with grey pollinosity; three large brown vittae as in figure 1, scutellum with a dark brown triangular area on center and two brown lateral areas on basal half. Calypters white; halter yellow; wing hyaline. Legs brown; pulvillus yellowish; claws yellow on basal half and black on apical. Abdomen marked as in figure 2; some specimens with lateral yellow areas on tergites 4 and 5 .
Length. Male: body 7.5-7.9 mm; wing 7.3-7.5 mm.

Head. Eye densely haired; holoptic, interocular space about 0.13-0.16 of head width, at level of anterior ocelli. Nine pairs of frontal setae, the three ones closer to antenna longer, fine hairs between the frontal setae. Inner and outer vertical seta delicate. Ocellar seta medium, similar in length with the upper frontals. Antena inserted a little below middle of eyes; flagellum about 3.0-3.2 times the pedicel. Arista with long plumae. Vibrissa strong and long; 5-7 supra and subvibrissal setulae.

Thorax. Acrostichal 0:1; dorsocentrals setae 2:4; 2 strong humerals; 1 post-humeral; 1 presutural and two 2 pos-sutural intra-alars; 2 supra-alars. Scutellum with one sub-basal, one lateral and one apical pair of bristles, all strong. Notopleuron with two long and similar bristles. Anepisternum with a row of about 10 bristles and many long cilia. Calypter inferior about 2.0-2.3. Fore femur with a complete posterodorsal, dorsal and anterodorsal row of setae. Fore tibia with one pre-apical dorsal and one posteroventral apical. Mid femur with an anterodorsal row of setae on basal half, longer at middle and an anteroventral complete row of short setae. Mid tibia with one posterior median seta, one submedian shorter, apical seta on posteroventral, anteroventral and ventral surfaces with apical seta, the last one longer. Hind femur with an anterodorsal and anteroventral row of setae and one dorsal preapical. Hind tibia with one median anteroventral seta, one short posteroventral and one pre-apical dorsal.

Abdomen. Tergites with no longer and distinct setae. Tergite 5 with fine setae on disk. Sternite 5 quadrangular with many setae on apical 3/4, 3 or 4 longer on lateral middle (Fig. 3). 

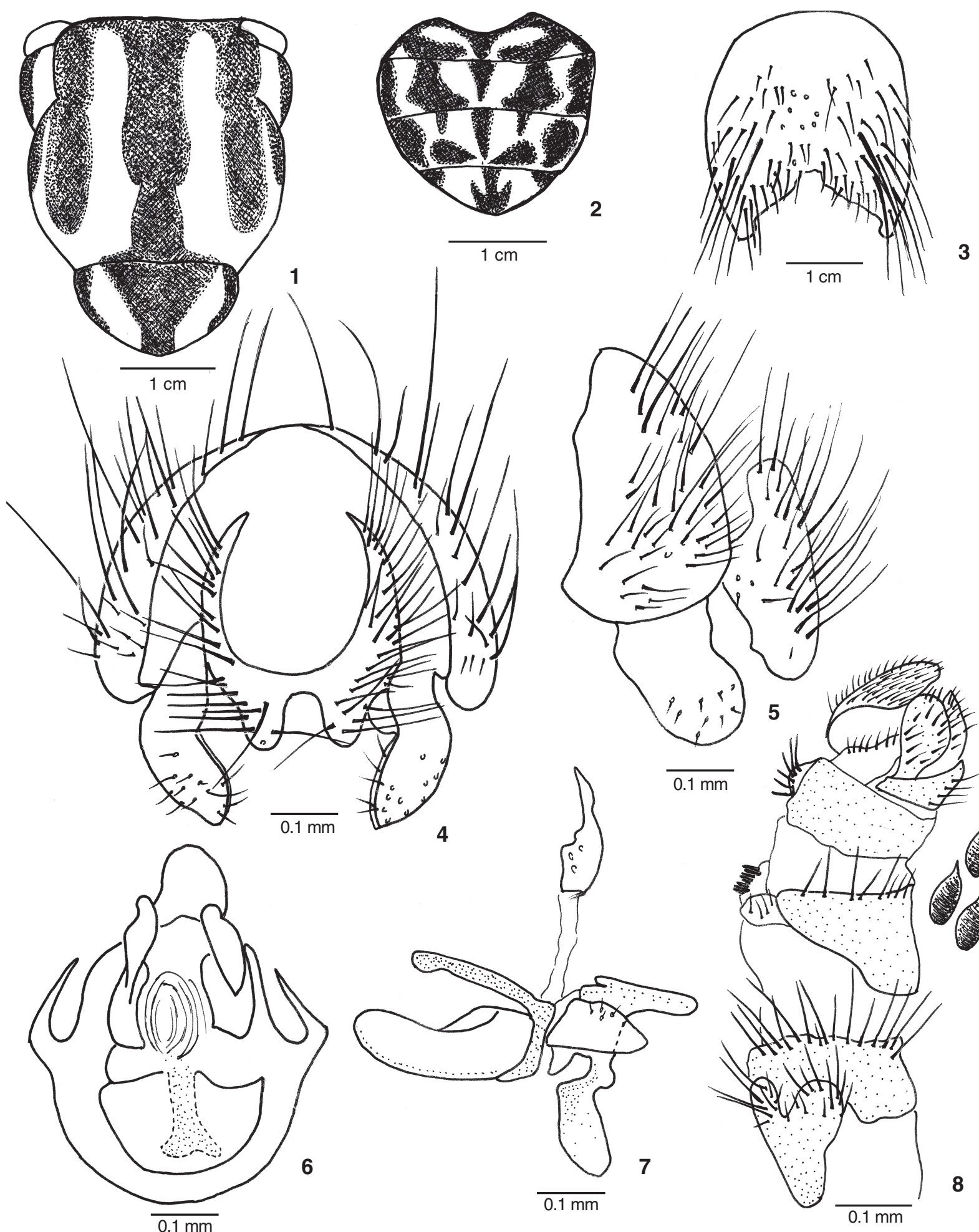
Terminalia. Cercal plate short on middle with two fine lateral arms, with long setae, specially laterally (Fig. 4 and 5). Phallic complex as in figures 6 and 7 .

Female: Length: body: 7.5-7.8 mm; wing: $7.4 \mathrm{~mm}$.

Similar to male differing as follows: Dichoptic, interocular space about one third of head width, at level of anterior ocelli.

Ovipositor medium sized, with large tergites and sternites; sternite 7 with short spines, sternite 8 with setae (Fig. 8). Three elongated spermathecae (Fig. 8).

Discussion. The marks on mesothorax and abdomen easily distinguishes $G$. amazonensis from its congeneres. Among the species occurring in Brazil, G. analis has the tergite 5 golden yellow, contrasting with the other tergites and G. meridionalis has the abdomen almost all yellow in colour. The marks at mesonotum are also different in the three species.

Material examined. Holotype male, BrazIL, Amazonas: Manaus (BR 17, Km 38), 9.VIII.1969, E.V. Silva leg. Paratypes: same locality and collector as holotype: 4 females, BR 17, 10.VIII.1969; 3 females,
BR 17, 5.VIII.1969; 2 females, BR 17, Km. 38, 17.VIII.1969; 1 female, BR 17, Km. 38, 9.VIII.1969; 1 female, BR 17, Km. 38, 9.VIII.1969; 1 female, BR 17, Km. 38, 7.VIII.1969; 1 female, BR 17, 12.VIII.1969; Reserva Ducke, 1 female, 18.VI.1976, L. Albuquerque leg.

\section{ACKNOWLEDGMENTS}

MSC gratified to CNPq for her research grant (process number 300386/80-0) for the financial support to the project.

\section{REFERENCES}

Carvalho, C.J.B. DE; M.S. Couri; A.C. Pont; D. Pamplona \& S.M. Lopes 2005. A Catalogue of the Muscidae (Diptera) of the Neotropical Region. Zootaxa, Auckland, 860: 1-282.

Couri, M.S. \& C.J.B. De Carvalho. 2002. Part II. Apical Groups. In: C.J.B. de Carvalho (Ed.). Muscidae (Diptera) of the Neotropical Region: taxonomy. Curitiba, Editora Universidade Federal do Paraná, p. 133-262.

Received in 01.III.2005; accepted in 22.VIII.2005. 